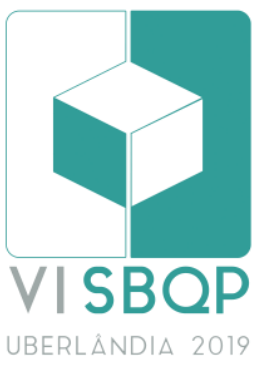

\title{
RESIDÊNCIA SUSTENTÁVEL SOB A ÓTICA DA CERTIFICAÇÃO GBC BRASIL CASA
}

\author{
ABRAHÃO, Karla C. F. J. \\ UFMG, e-mail: kjabrahao@hotmail.com \\ LIMA, Laura C. N. \\ UFMG, e-mail: la.carolina.Icn|@gmail.com
}

\begin{abstract}
RESUMO
O projeto arquitetônico é primordial para um empreendimento e os arquitetos, atualmente, buscam conciliar o meio ambiente natural e a construção de ambientes às tecnologias sustentáveis voltadas para a produção de edificações. As premissas projetuais vão desde à redução de impactos ambientais e à melhora na qualidade da saúde dos usuários, incluindo a recuperação e reutilização de edificações. Assim, este trabalho tem o objetivo de apresentar um estudo de caso, projeto residencial unifamiliar, desenvolvido com a aplicação de conceitos sustentáveis e critérios balizados pela certificação GBC Brasil Casa. Esse trabalho contribui com o mercado produtivo de edificações desse contexto ao concluir que a aplicação desses critérios é de fácil implementação com a capacidade de melhorar o nível de qualidade do ambiente construído e contribuindo para alcançar as metas estabelecidas pela Agenda 21 nas esferas municipais, estaduais e federais.
\end{abstract}

Palavras-chave: Sustentabilidade, Projeto arquitetônico, GBC Brasil Casa.

\section{ABSTRACT}

The architectural project is essential for an enterprise and architects are currently seeking to reconcile the natural environment and the construction of environments with sustainable technologies for the production of buildings. The design assumptions range from reducing environmental impacts and improving the quality of users' health, including the recovery and reuse of buildings. Thus, this paper aims to present a case study, single-family residential project, developed with the application of sustainable concepts and criteria marked by GBC Brasil Casa certification. This work contributes to the productive market of buildings in this context by concluding that the application of these criteria is easy to implement with the capacity to improve the level of quality of the built environment and contributing to the achievement of the goals set by Agenda 21 at the municipal, state and local levels.

Keywords: Sustainability, Architectural Design, GBC Brasil Casa.

\section{INTRODUÇÃO}

Este trabalho propõe o desenvolvimento de um projeto arquitetônico de uma residência unifamiliar com alternativas práticas sustentáveis, conscientes e menos agressivas à natureza, através de um estudo de caso. Para sua elaboração baseou-se nas diretrizes do Guia de Certificação GBC Brasil Casa, que fornece métodos para projetar, construir e operar uma residência sustentável e critérios de certificação para o alto nível de qualidade do ambiente construído. (GBC Brasil, 2017)

As certificações de sustentabilidade voltadas para edificações, de forma geral, estabelecem parâmetros de avaliação do projeto e seus sistemas

ABRAHÃO, K. C. F. J.; LIMA, L. C. N. Residência sustentável sob a ótica da certificação GBC Brasil Casa. In: SIMPÓSIO BRASILEIRO DE QUALIDADE DO PROJETO NO AMBIENTE CONSTRUÍDO, 6., 2019, Uberlândia. Anais... Uberlândia: PPGAU/FAUeD/UFU, 2019. p. 365-374. DOI https://doi.org/10.14393/sbqp19035. 
através de critérios permite quantificar os benefícios alcançados nos níveis ambiental, social e econômico. Essas certificações visam oferecer custos operacionais mais baixos e aumento do valor patrimonial; redução de resíduos enviados para aterros sanitários; conservação de energia e água; ambientes mais saudáveis e produtivos para ocupantes, redução das emissões de gases efeito estufa e outros.

As certificações GBC Brasil Casa e Condomínio, lançadas em 2012 como Referencial para Casas Sustentáveis pelo órgão Green Building Council Brasil, foram desenvolvidas para estimular e direcionar o mercado produtivo de edificações à enfrentar os desafios ambientais brasileiros e suas peculiaridades (GBC Brasil, 2017).

A certificação GBC Brasil Casa, voltada para residências unifamiliares, está na versão 2, juntamente com a certificação GBC Brasil Condomínio, voltada para residências multifamiliares. Em sua fase inicial a certificação contou com projetos pilotos em diversos estados brasileiros e hoje tem-se residências certificadas na última versão da certificação no estado do Paraná e São Paulo. (GBC Brasil, 2019).

O referencial técnico da certificação GBC Brasil possui uma estrutura composta por oito categorias de análise: Implantação (IMP); Eficiência Energética (EA); Uso Eficiente Água (UEA); Materiais e Recursos (MR); Qualidade Ambiental Interna (QAI); Requisitos Sociais (RS); Inovação e Projeto (IP) e Créditos Regionais (CR).

O sistema de avaliação é baseado em pré-requisitos, que são obrigatórios, e de créditos que são pontuáveis. Para se obter a certificação é necessário o atendimento de no mínimo 40 pontos. A pontuação estabelece o nível da classificação da certificação, sendo: $V E R D E=$ de 40 a 49 pontos, PRATA $=$ de 50 a 59 pontos, OURO = de 60 a 79 pontos e PLATINA $=80+$ pontos (GBC Brasil, 2017).

Nesse estudo são apresentadas algumas propostas sustentáveis para atender os requisitos da certificação GBC Casa, decidindo-se assim pela aplicabilidade da mesma como um modelo a ser seguido para residências sustentáveis. Entretanto, não é objetivo atingir pontuação para a obtenção da certificação

\section{METODOLOGIA}

Esta pesquisa classifica-se como estudo de caso, com uma pesquisa de caráter qualitativo e quantitativo. A primeira etapa consistiu no levantamento bibliográfico, levantamento de dados e das condicionantes legais municipais e bioclimáticas do local do projeto. A segunda etapa consistiu na elaboração do projeto, nas análises bioclimáticas e na seleção dos critérios da certificação para aplicação no projeto. A terceira etapa consistiu no desenvolvimento dos cálculos para atendimento aos critérios da certificação GBC Brasil selecionados, e na apresentação do projeto.

O projeto atendeu a legislação municipal, como o Código de Obras de Uberlândia - Lei n 4808 de 26 de outubro de 1988 e o Zoneamento do uso e ocupação do solo - Lei complementar $n^{\circ} 525$, de 14 de abril de 2011 . Baseouse nas diretrizes do Guia de Certificação GBC Brasil Casa, referencial técnico que fornece métodos para projetar, construir e operar uma residência 
sustentável e critérios de certificação para o alto nível de qualidade do ambiente construído (GBC Brasil, 2017).

A seleção de alguns dos créditos para aplicabilidade no estudo de caso teve como objetivo criar um modelo guia simplificado para o desenvolvimento de projetos de residências sustentáveis. Entretanto, nesse trabalho a ação de atingir pontuações e níveis de certificação não foi objetivo determinante.

\section{RESULTADOS E DISCUSSÃO}

O terreno está situado na cidade de Uberlândia (MG), Bairro Presidente Roosevelt - Zona Norte; Latitude: 18 54' 41" S - Longitude: 48 $18^{\circ}$ ' 21 ". O clima é mesotérmico, com verão quente e chuvoso e inverno ameno e seco, estando inserida na Zona Bioclimática 3 (ZB3) (ABNT, 2003).

Conforme a Lei Complementar $n^{\circ} 525$ de 14 de Abril de 2011, que dispõe sobre o parcelamento e zoneamento do uso e ocupação do solo, o terreno situa-se na zona classificada como Zona Residencial 2.

O projeto residencial desenvolvido tem área total de $387,61 \mathrm{~m}^{2}$, com ambientes distribuídos em dois pavimentos (Figuras 1 e 2).

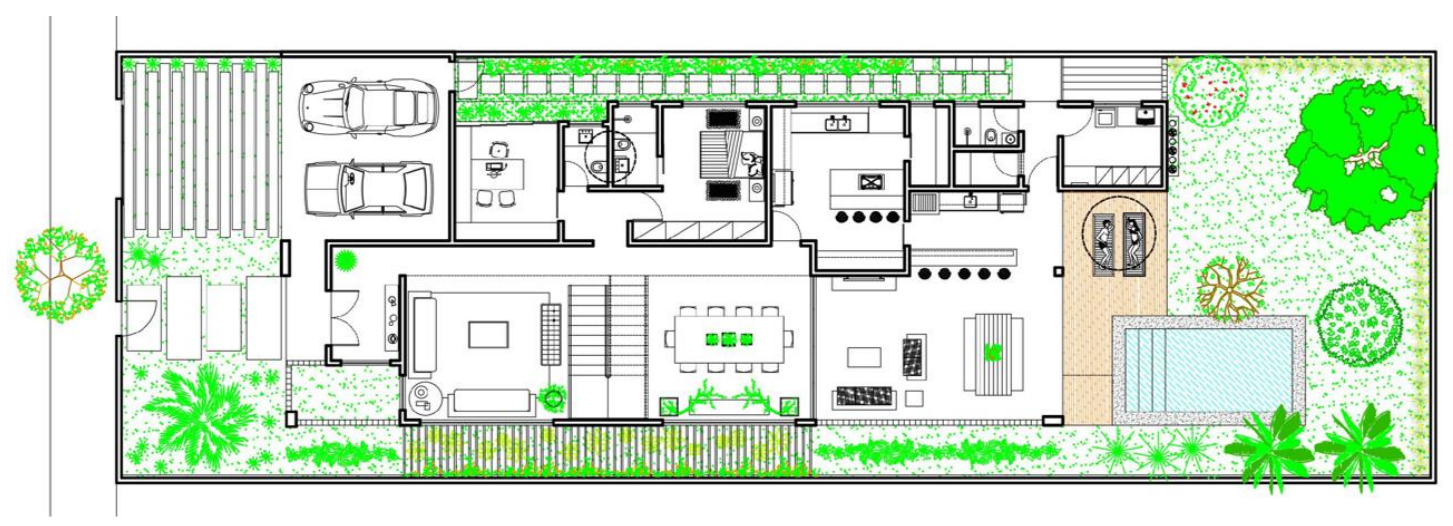

Figura 1 - Planta baixa pavimento térreo

Fonte: Autor (2018)

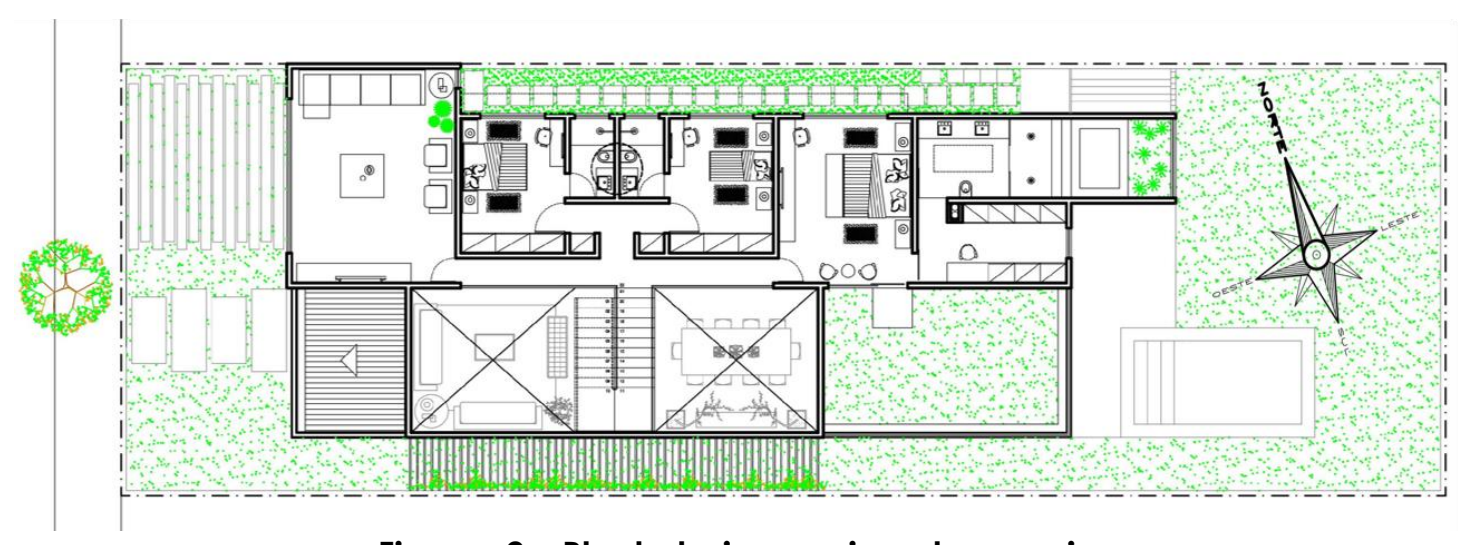

Figuras 2 - Planta baixa pavimento superior

Fonte: Autor (2018)

Para otimizar o aproveitamento do terreno e ofertar maior área verde, o projeto desenvolveu-se com implantação em formato retangular, com quatro fachadas definidas e paralelas aos limites do terreno, orientadas para norte- 
nordeste (Figura 3), leste-sudeste (Figura 4), sul-sudoeste (Figura 5) e oestenoroeste (Figura 6).

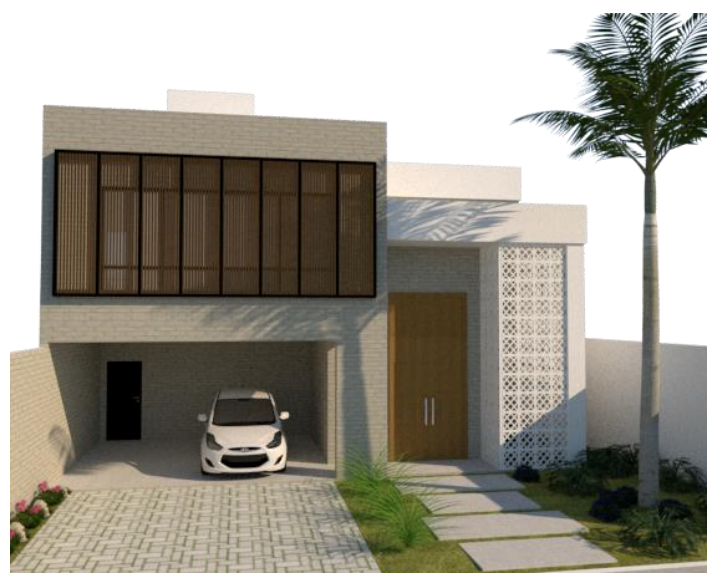

Figura 3 - Fachada norte-nordeste Fonte: Autor (2018)

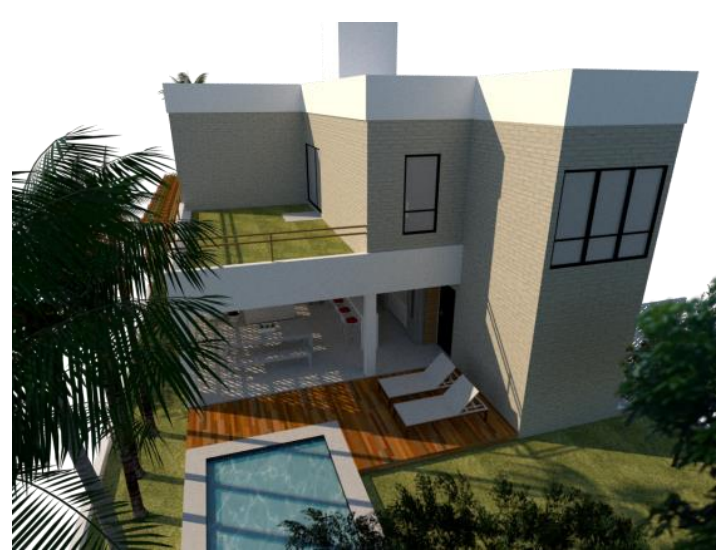

Figura 5 - Fachada sul-sudoeste Fonte: Autor (2018)

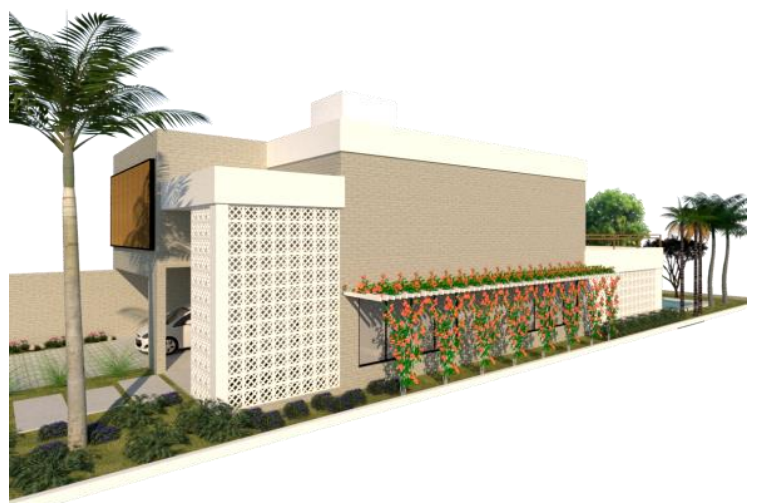

Figura 4 - Fachada oeste-noroeste Fonte: Autor (2018)

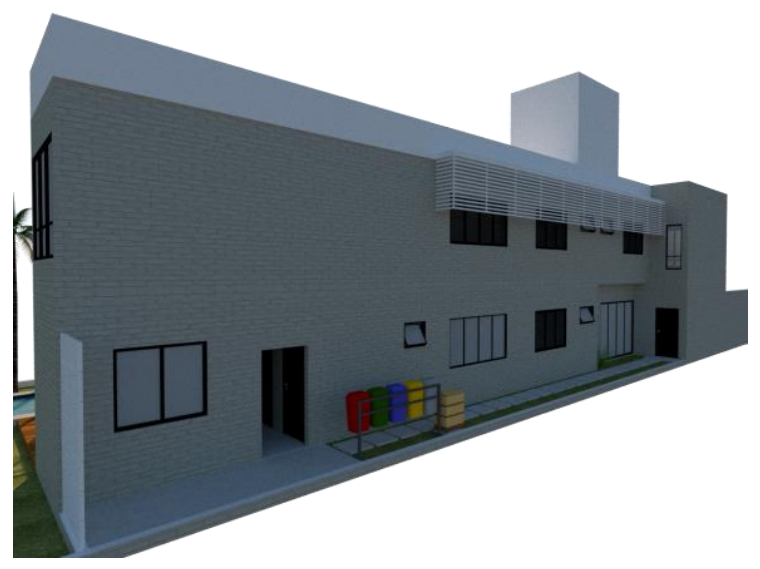

Figura 6 - Fachada leste-sudeste Fonte: Autor (2018)

\subsection{Seleção e análise de categorias, créditos e pré-requisitos}

Nesse item serão apresentados alguns critérios selecionados para aplicação no projeto desenvolvido a fim de torná-los como modelo guia simplificado com capacidade para contribuir com o projeto através de benefícios possíveis de serem alcançados nos níveis ambiental, social e econômico.

\subsubsection{Categoria Implantação (IMP)}

A Categoria Implantação almeja a integração da edificação e seus ocupantes, desde a escolha do terreno até a pós ocupação da residência buscando redução dos impactos ambientais e saúde e bem-estar das pessoas.

3.1.2 IMP - Pré-requisito 2 - Orientações na arquitetura bioclimática: foram aplicados no estudo de caso os conceitos de arquitetura bioclimática, como a análise da carta solar (Figura 7) para melhor orientação e distribuição dos cômodos quanto a insolação e ventos dominantes. Uma proposta projetual foi a introdução de um pergolado vegetado para proteção das esquadrias sul- 
sudoeste contra insolação e reduzindo a carga térmica e ganho de calor do ambiente.

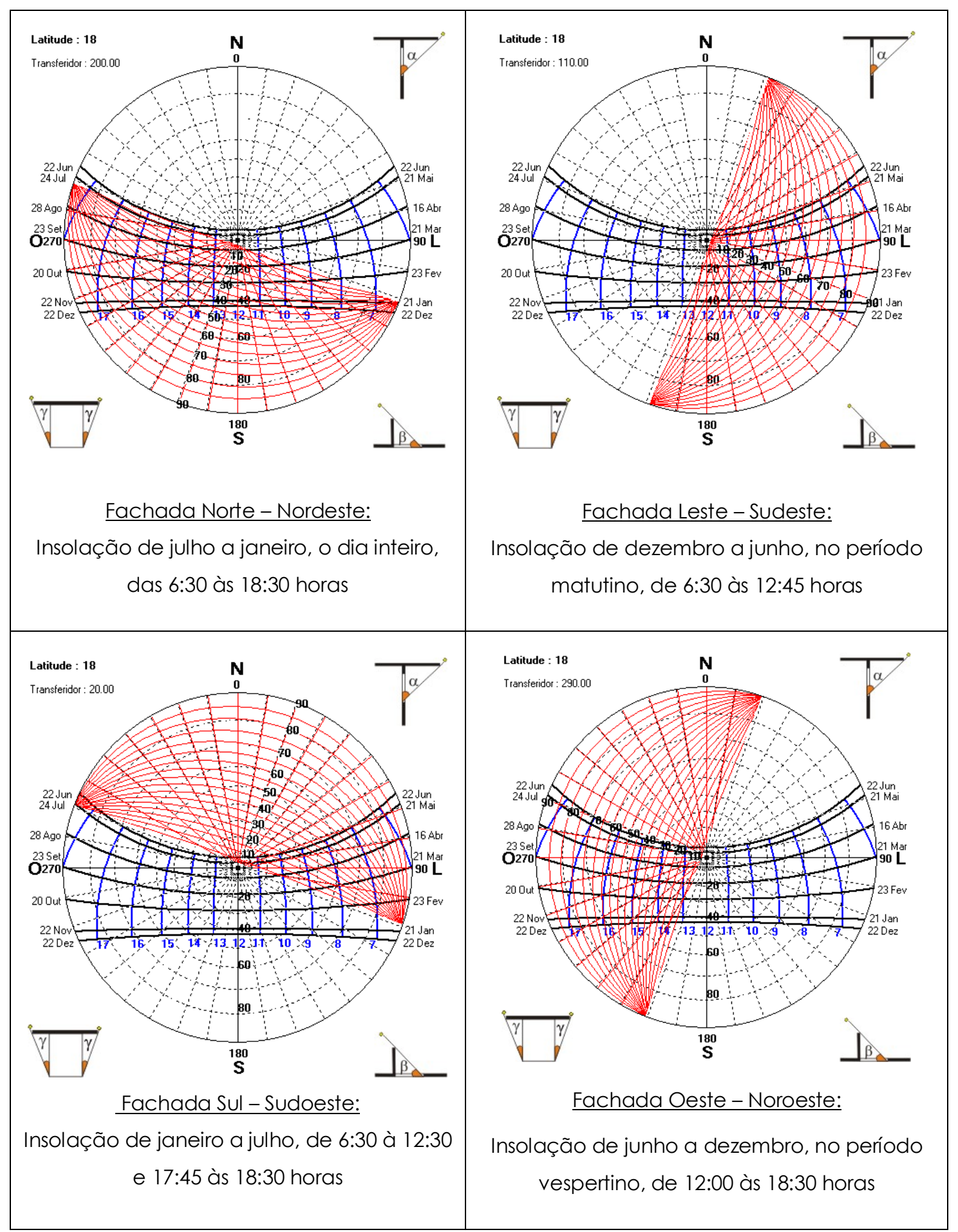

Figura 7 - Insolação Fachadas

Fonte: Software Sol-Ar 6.2 (2018)

Para aproveitamento da ventilação natural através da análise dos ventos predominantes foi proposto localizar as esquadrias de modo a favorecer a ventilação natural cruzada. Em relação aos materiais da envoltória foram prescritos o tijolo solo cimento para a vedação e esquadrias de PVC. Com 
objetivos de melhorar o conforto térmico foi prescrito a cobertura com telhas térmicas topcomfort, cor branca, com alto índice de refletância solar e telhado verde como estratégia para a ampliação da refletividade e redução da absorvidade térmica.

3.1.1.2 IMP - Crédito 5 - Proximidade a recursos comunitários e transporte público: permite acesso por deslocamento a pé e estabelecimentos comunitários na proximidade, como bancos, correios, supermercados, farmácias, escolas e outros.

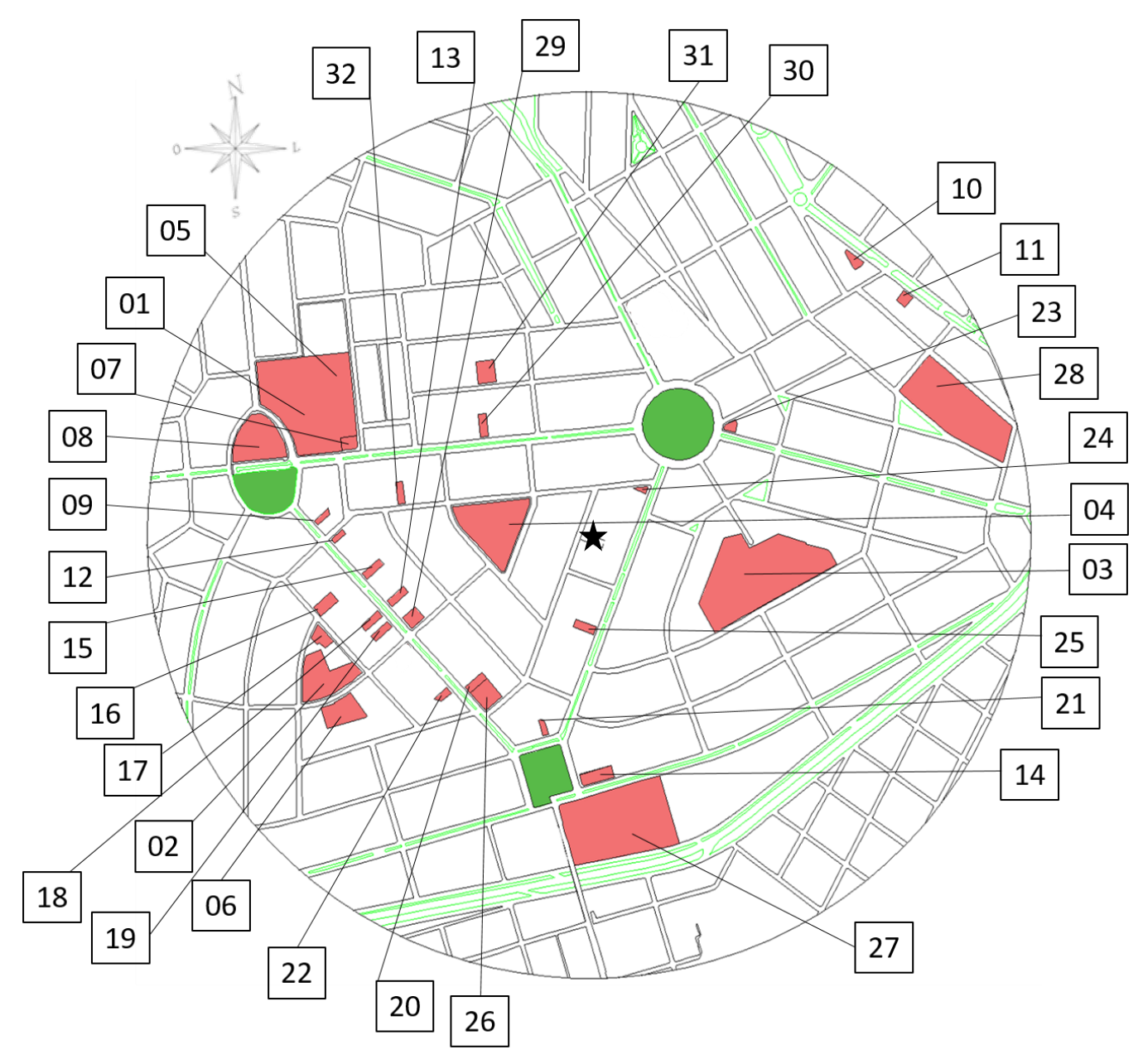

Figura 8 - Recursos Comunitários

Fonte: Autor (2018)

Tabela 1 - Recursos Comunitários

\begin{tabular}{|c|c|c|}
\hline \multicolumn{3}{|c|}{ RECURSOS COMUNITÁRIOS } \\
\hline $\begin{array}{c}\text { ITE } \\
\text { M }\end{array}$ & DESCRIÇÃO & DISTÂNCIA \\
\hline 01 & Escola Estadual Guiomar de Freitas Costa & 700 metros \\
\hline 02 & Escola Municipal Professora Maria Leonor de Freitas & 750 metros \\
\hline 03 & $\begin{array}{c}\text { SENAI Uberlândia Fábio de Araújo Motta / SESI Uberlândia Guiomar } \\
\text { de Freitas Costa }\end{array}$ & 650 metros \\
\hline 04 & Escola Estadual Padre Mário Forestan & 350 metros \\
\hline 05 & EMEl Eurípedes Rocha & 700 metros \\
\hline 06 & EMEl Roosevelt & 650 metros \\
\hline 07 & Posto de saúde & 650 metros \\
\hline
\end{tabular}




\begin{tabular}{|c|c|c|}
\hline 08 & Paróquia São Judas Tadeu & 800 metros \\
\hline 09 & Agência Lotérica & 650 metros \\
\hline 10 & Agência Bancária & 950 metros \\
\hline 11 & Agência Bancária & 1.000 metros \\
\hline 12 & Farmácia & 650 metros \\
\hline 13 & Farmácia & 550 metros \\
\hline 14 & Farmácia & 600 metros \\
\hline 15 & Academia de Ginástica & 600 metros \\
\hline 16 & Academia de Ginástica & 750 metros \\
\hline 17 & Fundação de Ação Social Evangélica - Alcoólicos Anônimos & \\
\hline 18 & Clínica veterinária 24 horas & 550 metros \\
\hline 19 & Consultório odontológico & 510 metros \\
\hline 20 & Consultório odontológico & 400 metros \\
\hline 21 & Consultório odontológico & 430 metros \\
\hline 22 & Padaria & 400 metros \\
\hline 23 & Padaria / Restaurante & 350 metros \\
\hline 24 & Restaurante & 230 metros \\
\hline 25 & Restaurante & 230 metros \\
\hline 26 & Quadra esportiva & 350 metros \\
\hline 27 & Supermercado & 550 metros \\
\hline 28 & Mercado & 1.000 metros \\
\hline 29 & Slube Recreativo & 500 metros \\
\hline 30 & Cercado Atacado / Varejo & 450 metros \\
\hline 31 & Instituto Circo da Vida - Rede Cultura Real & 550 metros \\
\hline 32 & Fon \\
\hline
\end{tabular}

Fonte: Autor (2018)

Nessa categoria compreende-se que a localização do terreno situado em área pré-desenvolvida apresenta benefícios aos usuários da residência como estímulo à realização de caminhadas, diversidade de recursos comunitários que reduzem a necessidade de deslocamento, além da mobilidade garantida pelo fácil acesso a rede de transporte público da cidade que permeia o bairro e conta com pontos próximos a residência.

\subsubsection{Categoria Uso Eficiente da Água (UEA)}

A Categoria Uso Eficiente da Água busca um equilíbrio no consumo de água, redução do consumo de água potável ou adoção de fontes alternativas, como captação de água fluvial ou reuso de água. Permite monitoramento do consumo da água e uma boa qualidade e segurança da água.

3.1.2.1 UEA - Pré-requisito 1 - Uso eficiente da água - básico: utilizados equipamentos hidráulicos eficientes, de vazão constante, dotados de arejadores e restritores de vazão. Atende aos $90 \%$ exigidos pelo pré-requisito, através da fórmula, obtida pela divisão ente a quantidade total de equipamentos eficientes e a quantidade total de pontos hidrossanitários multiplicados por cem. O valor obtido foi $90,62 \%$.

Tabela 2 - Equipamentos Hidráulicos

\begin{tabular}{|c|c|c|c|}
\hline \multicolumn{3}{|c|}{ EQUIPAMENTOS HIDRÁULICOS } \\
\hline \multirow{2}{*}{ ITEM } & EQUIPAMENTO & $\begin{array}{c}\text { VAZÃO NA } \\
\text { PRESSÃO } \\
\text { MÍNIMA }\end{array}$ & $\begin{array}{c}\text { QUANTIDAD } \\
\text { E }\end{array}$ \\
\hline 01 & Bacia Deca convencional Carrara com válvula de \\
descarga - Deca Hydra Duo & $6 \mathrm{~L} / \mathrm{min}$. & 06 \\
\hline 02 & Ducha higiênica com registro e derivação - Deca & $5 \mathrm{~L} / \mathrm{min}$. & 06 \\
\hline
\end{tabular}




\begin{tabular}{|c|c|c|c|}
\hline & Duna Quadratta & \\
\hline 03 & $\begin{array}{c}\text { Misturador de mesa bica alta - Deca Duna } \\
\text { Quadratta }\end{array}$ & $5 \mathrm{~L} / \mathrm{min}$. & 07 \\
\hline 04 & $\begin{array}{c}\text { Chuveiro com entrada de ar e tubo de parede } \\
\text { Deca Acqua Plus Quadratta }\end{array}$ & $12 \mathrm{~L} / \mathrm{min}$. & 06 \\
\hline 05 & Misturador de mesa para cozinha Deca Axis & $4 \mathrm{~L} / \mathrm{min}$. & 03 \\
\hline 06 & Torneira com arejador para tanque Deca Izy & $6 \mathrm{~L} / \mathrm{min}$. & 01 \\
\hline 07 & $\begin{array}{c}\text { Torneira de tanque com derivação para máquina } \\
\text { Deca lzy }\end{array}$ & $11 \mathrm{~L} / \mathrm{min}$. & 01 \\
\hline 08 & $\begin{array}{c}\text { Torneira para jardim com adaptador de mangueira } \\
\text { Deca lzy }\end{array}$ & $11 \mathrm{~L} / \mathrm{min}$. & 02 \\
\hline
\end{tabular}

Nessa categoria compreende-se a relevância da especificação dos equipamentos hidráulicos por parte de profissionais capacitados, que auxiliarão os moradores na redução do consumo de água bem como no reuso dessa ou no uso de água pluvial.

\subsubsection{Categoria Energia e Atmosfera (EA)}

A Categoria Energia e Atmosfera (EA) busca uma redução no consumo energético por meio de sistemas eficientes e do desempenho energético da residência. Estimula o uso de fontes de energia renováveis, reduzindo ou evitando danos ambientais e conforto térmico.

3.1.3.1 EA - Pré-requisito 2: Fontes de aquecimento de água eficientes: foi dotada de sistema de aquecimento de água solar.

3.1.3.4 EA -credito 7 - Energia Renovável: foi dotada de sistema de geração de energia renovável por painéis fotovoltaicos. A geração em $90 \%$, dimensiona o sistema para instalação de nove módulos fotovoltaicos, com payback de pouco mais de dois anos.

Nessa categoria compreende-se a possibilidade do desempenho energético de uma residência sustentável por meio da análise bioclimática realizada na Categoria Implantação, da especificação do sistema de iluminação eficiente e pelo uso de energias renováveis, como nesse caso a solar.

\subsubsection{Categoria Materiais e Recursos (MR)}

A Categoria Materiais e Recursos orienta a escolha de materiais sustentáveis para redução de resíduos gerados pela construção. O uso de materiais regionais, o reuso de materiais ou o uso de materiais com porcentagem reciclada em sua são estratégias que buscam aumentar o ciclo de vida dos produtos visando a utilização de materiais ambientalmente preferíveis, combatendo materiais tóxicos ou contaminantes.

3.1.4.1 MR - Crédito 4 - Rotulagem ambiental tipo II - materiais ambientalmente preferíveis: materiais regionais, como o tijolo solo cimento, fabricado na própria cidade de Uberlândia.

Nessa categoria compreende-se quão extenso é o impacto causado pela extração de elementos naturais para produção de materiais de construção, bem como são fabricados e os resíduos que geram nesse processo e durante todas as fases de construção e demolição de uma edificação. 


\subsubsection{Categoria Qualidade Ambiental Interna (QAI)}

A Categoria Qualidade Ambiental Interna apresenta estratégias e requisitos a fim de evitar e reduzir a polvição do ambiente interno. Proporcionar a ventilação natural dos ambientes através de condicionantes climáticas locais é uma estratégia para a renovação do ar e a dispersão de partículas contaminantes oriundas dos materiais do ambiente. Adicionalmente, essa categoria prioriza o conforto térmico e lumínico, essenciais para a saúde e bem estar dos residentes.

\subsubsection{Categoria Requisitos Sociais (RS)}

A Categoria Requisitos Sociais busca a formalidade nos tópicos socioambientais, procurando, durante a execução da obra minimizar impactos gerados, proporcionando redução de danos.

3.1.6.1 RS - Créditol - Acessibilidade Universal: O pavimento térreo foi projetado em um plano horizontal sem desníveis, portas com largura mínima de $80 \mathrm{~cm}$ para acesso aos ambientes, garantindo acessibilidade.

Nessa categoria compreende-se o social no tripé da sustentabilidade (social, econômico e ambiental), priorizando questões trabalhistas e capacitação dos profissionais além de legitimar empresas e indústrias perante os órgãos competentes. Quanto à parte projetual da construção, foca no ser humano e suas necessidades especiais, sejam elas permanentes ou passageiras, difundindo o conceito do desenho universal.

\subsubsection{Categoria Inovação e Projeto (IP)}

A Categoria Inovação e Projeto bonifica a inovação nas construções sustentáveis por meio do projeto integrado, com, pelo menos, um profissional acreditado pelo GBC Brasil na equipe. Incentiva o uso de tecnologias e métodos com nível superior aos exigidos nos pré-requisitos e créditos do guia e devem estar descritas no Manual do Usuário.

Nessa categoria compreende-se a necessidade da comunicação entre os profissionais das diversas áreas e etapas responsáveis desde o projeto até a execução da obra, garantindo assim alto nível de eficiência e desempenho para a residência bem como sistemas que funcionem em harmonia.

\subsubsection{Categoria Créditos Regionais (CR)}

A Categoria Créditos Regionais nesse trabalho adotou as práticas regionais do Sudeste.

A partir da seleção dos critérios apresentados nesse trabalho desenvolveu-se um projeto residencial aplicando conceitos sustentáveis e critérios embasados pelo programa GBC Brasil Casa. A maior contribuição foi apresentação de uma seleção de critérios tais como um modelo guia simplificado e sua aplicação no estudo de caso, concluindo que este apresentou fácil aplicabilidade com benefícios de melhoria do nível da qualidade do ambiente construído.

\section{CONSIDERAÇÕES FINAIS}

O estudo de caso possibilitou a prática profissional de projetar uma residência com estratégias sustentáveis voltada para o ambiental, social e econômico e a aplicabilidade de uma certificação ambiental para edificação. Além disso, 
permitiu definir as melhores práticas projetuais para a zona bioclimática e entorno na qual o projeto está inserido.

\section{REFERÊNCIAS}

ASSOCIAÇÃO BRASILEIRA DE NORMAS TÉCNICAS- ABNT. NBR 15520.

Desempenho térmico de edificações. Parte 3. Rio de Janeiro. Set/2003.

GREEN BUILDING COUCIL BRASIL (GBC Brasil) - Guia de Certificação GBC Brasil Casa - Segunda Versão. GBC, 2017.

GREEN BUILDING COUCIL BRASIL (GBC Brasil) - Empreendimentos Registrados Disponível em:

$<$ http://www.gbcbrasil.org.br/empreendimentoscasa.php?inicio $=0 \& q=\&$ construtora $=>$. Acesso: 05/2019.

PREFEITURA MUNICIPAL DE UBERLÂNDIA. Código de Obras de Uberlândia - Lei n 4808 de 26 de outubro de 1988. Disponível em:

$<$ www.leismunicipais.com.br/prefeitura/mg/uberlandia>. Acesso: 10/2017. PREFEITURA MUNICIPAL DE UBERLÂNDIA. Zoneamento do uso e ocupação do solo. Lei complementar $n^{\circ} 525$, de 14 de abril de 2011 . Disponível em: <www.leismunicipais.com.br/prefeitura/mg/uberlandia>. Acesso: 10/2017.

PREFEITURA MUNICIPAL DE UBERLÂNDIA. BDI - Banco de dados integrados. Disponível em: < www.uberlandia.mg.gov.br/2014/secretariapagina/56/514/banco de dados integrados bdi.html >. Acesso em: 04 set. 2018. 